\title{
EDUCAÇÃO ATRAVÉS DA ARTE PARA UM FUTURO SUSTENTÁVEL
}

\author{
Teresa Torres Pereira de Eça
}

\begin{abstract}
RESUMO: Este artigo fundamenta que a arte e a educação através da arte têm um papel importante na construção de um futuro sustentável porque promovem criatividade, inovação e pensamento crítico, capacidades fundamentais para uma cultura emancipadora, de igualdade e responsabilidade social, e condições essenciais para o desenvolvimento de um futuro sustentável. Pela sua natureza holística, a educação através da arte pode, quando direcionada para a educação para a cidadania e para os valores, transformar o currículo e recriar a escola por meio de projetos transdisciplinares, quebrando as barreiras entre áreas do saber e proporcionando espaços únicos de aprendizagem. No entanto, para que tal aconteça é preciso rever e reformular os paradigmas atuais da educação e as abordagens da educação através da arte e, sobretudo, apostar mais na formação de educadores e professores.
\end{abstract}

Palavras-chave: Educação artística. Arte e educação. Criatividade. Educação para a cidadania. Desenvolvimento sustentável.

\section{EDUCATION TROUGH ART FOR A SUSTAINABLE FUTURE}

ABSTRACT: Education through art has a crucial role in the development of a sustainable development because it promotes creativity, innovation and critical thinking. Such skills are necessary to acquire an emancipating culture of equality and social responsibility, essential conditions to develop a sustainable future. If directed towards

PhD, professora de Desenho na Escola Secundária Alves Martins, de Viseu, e Investigadora do Centro de Investigação em Educação e Psicologia da Universidade de Évora (Portugal).E-mail: teresatorreseca@gmail.com 
citizenship and education for values, the holistic nature of art education may transform the curriculum and reform school through transdisciplinary projects breaking boundaries between knowledge areas and enabling unique learning sites. However, this will only be possible if we reformulate current education paradigms and art education approaches and teacher training.

Key words: Artistic education. Art and education. Creativity. Citizenship education. Sustainable development.

\section{Sustentabilidade}

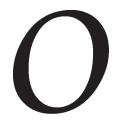

conceito de desenvolvimento sustentável é, normalmente, definido como o desenvolvimento que procura satisfazer as necessidades da geração atual, sem comprometer a capacidade das gerações futuras de satisfazerem as suas próprias necessidades; significa possibilitar que as pessoas, agora e no futuro, atinjam um nível satisfatório de desenvolvimento social e econômico e de realização humana e cultural, fazendo, ao mesmo tempo, um uso razoável dos recursos da terra e preservando as espécies e os habitats naturais.

O filósofo István Mészáros, no seu discurso da Cimeira dos Parlamentos Latino-Americanos sobre a "dívida social e integração latinoamericana" (em Caracas, 2001), chamava a atenção para o fato de que o desafio do desenvolvimento sustentável requer grandes mudanças sociais, políticas e econômicas nomeadamente no nosso entendimento do que é a igualdade. Nas nossas sociedades, a desigualdade material é alicerçada pelo modo como os indivíduos interiorizam o seu "papel na sociedade", mais ou menos consensualmente, resignando a sua categoria de subordinação aos que tomam decisôes sobre as suas vidas. Esta atitude social sempre acompanhou as estruturas de desigualdade do capital, existindo uma interação recíproca entre as estruturas materiais reprodutivas e a dimensão cultural, criando um círculo vicioso que prendeu a esmagadora maioria dos indivíduos a comportamentos de subordinação acrítica. Para caminharmos em direção a um futuro sustentável, necessitamos trabalhar para uma cultura emancipadora. Mészáros diz que, numa alteração qualitativa para o futuro, o papel vital do processo cultural não pode ser subestimado, pois não pode haver uma fuga ao círculo vicioso da desigualdade, a menos que desenvolvamos alguma espécie de interação numa direção emancipadora e 
crítica: "O sucesso requer a constituição de uma cultura de igualdade substancial, com o envolvimento activo de todos, e a consciência da nossa própria partilha de responsabilidade implícita na operação de um tal modo de tomada de decisões sem-adversariedade" (Mészáros, 2001).

Parece-nos que, para concretizarmos essa mudança, para que exista envolvimento ativo de todos, necessitamos de mais responsabilidade social e consciência do papel da humanidade no planeta. Isso só poderá ser feito a longo prazo se as comunidades, os poderes locais, regionais e nacionais se convencerem da importância da educação, tanto em contextos formais como não formais. Não de uma educação obsoleta fragmentada em disciplinas estanques, em horários compartimentados, em lobbies de áreas do saber, em escolas rotineiras ou eventos pontuais de instituições culturais. Necessitamos de um novo paradigma para a educação, de planos concertados entre lugares de aprendizagem, de novas formas de ensinar, aprender e avaliar que desenvolvam o pensamento crítico e independente, a imaginação, o sentido de risco, a curiosidade pelo conhecimento, a facilidade de comunicação em todas as áreas de expressão e conhecimento, tendo em conta as diversidades individuais e culturais.

\section{Educação}

As escolas têm a missão de desenvolver as múltiplas formas da literacia, ou seja, o desenvolvimento das capacidades dos alunos através da arte, das ciências, da matemática e outras formas sociais por meio das quais o significado é construído (Efland, 1999). A educação pode, a longo prazo, fazer face a problemas graves do planeta, pode preparar os jovens para o desenvolvimento sustentável e harmonioso, pode ser o único caminho para preservar identidades, sistemas econômicos e equilíbrios ecológicos. O grupo da World Arts Alliance apelava, em 2006, para novos e mais adequados paradigmas da educação que transmitam e transformem a cultura através das linguagens humanistas da arte, baseadas nos princípios da cooperação e não da competição.

Caberia aos políticos e à sociedade civil, por meio dos seus representantes, definir as grandes metas da educação que preparassem as nossas crianças para o futuro. John Steers, numa comunicação na Conferência da Associação de Professores de Expressão e Comunicação Visual (APECV), em 25 de novembro de 2008, no Instituto Superior da 
Maia (ISMAI), em Portugal, descreveu a preocupação do governo britânico em assegurar a estabilidade social e o desenvolvimento econômico. Numa sociedade multi-étnica, multicultural e multi-religiosa como a do Reino Unido, a estabilidade e a harmonia ocupam um lugar de destaque na agenda política, nestes tempos conturbados, onde existe uma imigração a uma escala global sem precedentes. Daí, por exemplo, a importância da identidade cultural, da participação cívica, do desenvolvimento sustentável e da globalização como temas transdisciplinares do novo currículo que estão a desenhar com a ajuda das associações profissionais de professores, como a National Society for Education in Art and Design (NSEAD).

A cultura e as indústrias criativas têm um peso econômico que não devemos menosprezar. Ciente disso, o governo britânico está neste momento a implementar um novo currículo, onde a criatividade e a transdisciplinaridade são os eixos essenciais. Neste contexto, a arte e a educação artística têm um papel-chave a desenvolver. São também essenciais os eixos transversais da educação para a cidadania, da educação ambiental e da educação para os valores e existe cada vez mais consciência política de que a educação deveria reformular a sua estrutura fragmentária disciplinar e redefinir-se em moldes transdisciplinares de projetos de trabalho a partir destes eixos. Estas razóes para a mudança têm implicações muito grandes na definição da educação artística, porque, por excelência, o ensino através da arte e das culturas pode incluir todos esses eixos e proporcionar terrenos transdisciplinares, quebrando as barreiras disciplinares sem perder a sua especificidade. A arte pode levar ao desenvolvimento de um amplo leque de qualidades criativas e capacidades críticas. A arte pode ser o centro do currículo e, se não quisermos que a educação artística seja marginalizada, é vital que os educadores artísticos compreendam o potencial da sua área e reestruturem as suas práticas, em parte para servir a estes fins.

O capital criativo é um fator-chave na economia sustentável. Uma boa educação através da arte pode ajudar os estudantes a verem melhor, a serem persistentes, ousados, e a aprenderem com os erros, fazendo juízos críticos e sabendo justiçar as sãs opiniões, tal como foi explicado pela equipe de investigação de Ellen Winner e Lois Hetland, da Universidade de Harvard (Hetland et al., 2007). O valor da educação através da arte não é desprezado nas famílias ricas que enviam os 
seus filhos para classes extraordinárias de dança, teatro, música ou artes plásticas, mas é completamente ignorado pela população em geral, que apenas compreende o valor da matemática como fator de sucesso. Cabe aos educadores uma responsabilidade social enorme, que é a de fazer visível o benefício que a educação através da arte traz para os estudantes. E, para isso, é necessário um esforço enorme de justificação constante.

A arte e a educação através da arte são campos ambíguos que se interpenetram. Artistas contemporâneos e/ou educadores e professores estão trabalhando em projetos sociais sem autoria, em bairros desfavorecidos, com populações de risco, com pessoas especiais, com presos, com doentes, com crianças, com adultos retomando o papel do artista xamã, providenciado experiências de conhecimento de si e do mundo através da arte. Esses artistas escapam às definiçóes do mercado da arte elitista. Do mesmo modo, existem professores de Arte que escapam às rotinas medíocres das escolas e ajudam os seus alunos, possibilitando experiências transversais de aprendizagem com a arte e pela arte, sem a pretensão de formar artistas ou públicos, mas sim de atingir um futuro sustentável, onde os indivíduos sejam mais criativos, mais críticos e mais solidários; onde pequenas populações possam cultivar as suas diferenças culturais, compreender, valorizar e praticar antigas produções artísticas, criar empregos, gerar turismo cultural e estabilidade social.

Se pensarmos nos benefícios a longo prazo destas práticas educativas nas comunidades, poderemos entender como o papel da educação através da arte é importante na sociedade.

\section{O Ano Europeu da Criatividade e da Inovação}

Parece que, nestes tempos, a criatividade está finalmente na agenda política da Europa. Nas Conclusóes do Conselho e dos Representantes dos Governos dos Estados-Membros, reunidos no dia 22 de maio de 2008, lia-se sobre a promoção da criatividade e inovação através da educação e formação (2008/C 141/10): ${ }^{1}$

A criatividade é a principal fonte de inovação, que, por sua vez, é considerada o principal motor de crescimento e riqueza, enquanto factor fundamental para melhorias no domínio social e instrumento essencial para enfrentar desafios globais, como as alteraçôes climáticas e o desenvolvimento sustentável. 
O Ano Europeu da Criatividade e da Inovação surge na sequência e como continuidade do Ano Europeu do Diálogo Intercultural (2008). O objetivo do Ano Europeu é promover a criatividade junto de todos os cidadãos, como motor de inovação e fator essencial do desenvolvimento de competências pessoais, profissionais, empresariais e sociais, contribuir para o intercâmbio de experiências e boas práticas, estimular a educação e a pesquisa e promover o debate político e o desenvolvimento. Procurando respeitar o conceito de aprendizagem ao longo da vida, cuja importância foi realçada na Resolução do Conselho, de 27 de junho de 2002, a promoção da criatividade e da capacidade de inovação deverá ser ajustada a todas as fases dessa aprendizagem, desde a educação pré-escolar e ao longo do período de formação e ensino obrigatório e pós-obrigatório, prosseguindo durante toda a vida.

\section{Criatividade}

Podemos atentar para centenas de definições de criatividade e, rapidamente, vemos que esta pode ser pensada como um ato, um conceito, uma estratégia ou até uma ideologia tácita. Partindo de uma definição aproximada de criatividade ensaiada por Pope (2005, p. xvi), esta seria a "(...) capacidade de produzir, fazer, ou tornar algo em uma coisa nova e válida tanto para si como para os outros". É um atributo humano comum. A maioria das pessoas resolve problemas de todas as espécies no seu dia a dia com algum grau de criatividade. Mas é um atributo que raramente encontramos no topo das prioridades escolares. Criatividade implica incerteza, desconhecimento, e não é fácil de ser avaliada. Por isso, ela fica muitas vezes à margem dos currículos.

\section{Criatividade nas escolas}

As escolas são instituições sociais que dão muito valor a certo grau de conformismo. A escola tende para um ambiente feito de certezas e "seriedade", onde o jogo não entra. Os horários rígidos e os prazos de entrega de trabalhos não permitem habilidades para concentração e persistência. A escola dificilmente fomenta associações insólitas e ideias aparentemente desconexas, e a vontade de explorar é tolhida muito cedo por questões de calendarização ou de cumprimento de programas rígidos. Já para não falar na dificuldade em aceitar comportamentos 
inconformistas, ousados ou arriscados (Steers, 2008). Na escola vive-se rotineiramente, joga-se pelo seguro, para os alunos terem bons resultados nos exames, porque a escola e a sociedade acreditam que ter resultados nos exames é um passaporte para o sucesso na vida futura. E os exames, normalmente, avaliam conhecimentos e capacidades que não são necessariamente importantes para um futuro sustentável.

Para que as escolas promovam ativamente a criatividade em cada criança, temos um grande caminho a percorrer, temos que virar tudo do avesso. E isso vai criar muitos problemas a toda a gente que trabalha no setor da educação. A criatividade requer um tipo de "espaço" raro nas escolas dirigidas por objetivos que dificilmente poderão deixar entrar o acidental das descobertas não esperadas que surgem, às vezes, quando se procuram outras coisas completamente diferentes (idem, ibid.).

Existem outras preocupações igualmente importantes, tanto para professores como para alunos, como, por exemplo, a construção de uma atmosfera forte de confiança mútua e suporte afetivo. Confiança e afetos não são o forte das escolas europeias geridas por regras e regulamentos baseados na desconfiança e no medo.

O uso construtivo de métodos sensíveis de questionamento é essencial para promover uma boa atmosfera de ensino e aprendizagem. Devemos permitir que os alunos desenvolvam um sentido real de autoria das tarefas, problemas ou trabalhos, e devemos fomentar a sua autoconfiança através de um feedback positivo. Contudo, essa atmosfera de suporte afetivo e desafio intelectual passa por espaços físicos agradáveis, aconchegados, passa por turmas com poucos alunos para que o diálogo e o feedback construtivo sejam possíveis. Isso não se assemelha à escola de massas que temos, com turmas de 30 alunos em espaços institucionais visualmente frios. Como poderemos fazer abordagens mais personalizadas, centradas no aluno - incluindo os dotados de talentos especiais - e adaptadas às suas necessidades e capacidades? Só com uma grande mudança da instituição, que terá de repensar a sua organização interna para aumentar a motivação e confiança de alunos. Essa mudança terá de partir de resoluções governamentais que, em vez de dar prioridade a cortes orçamentais, deveriam dar prioridade ao futuro sustentável dos países e à educação para esse futuro.

Todavia, as condiçóes conducentes ao desenvolvimento da criatividade na educação não dependem somente dos governos, mas também 
dos professores. Muitas vezes, nas ações de formação contínua para professores que tenho conduzido, ouço professores dizerem como são criativos e inovadores, como conseguem promover a criatividade e a inovação dos seus alunos. Mas, quando começo a fazer-lhes perguntas sobre as suas práticas pedagógicas, observo que os seus procedimentos são rotineiros, conformistas, e que as tarefas que propõem aos alunos não têm nada de criativo nem fomentam inovação. Existe um tremendo mal entendido sobre como fomentar a criatividade e a inovação nas concepções destes professores. Seria necessária uma grande aposta na formação de professores, inicial e contínua, de qualidade, para que a escola possa enfrentar o desafio lançado pelo Conselho Europeu, que dizia: “(...) aos professores cabe o papel crucial de estimular e apoiar o potencial criativo de cada criança e, para tanto, podem contribuir dando mostras de criatividade no seu próprio ensino".

\section{Aprendizagem individualizada}

Está na hora de deixar de lado a escola de massas, regularizadora e normativa, e apostar num sistema de educação que visa igualdade e excelência. ${ }^{2}$ Os ingleses já estão a trabalhar nesse sentido. Esses sistemas apóiam-se em métodos de aprendizagem individualizada, em princípios de aprendizagem que começam pelo conhecimento existente do aluno e o envolvem no processo de aprendizagem, que desenvolvem suas capacidades metacognitivas através do entendimento de propósitos, critérios, qualidades a atingir e valorizam a autoavaliação.

Um sistema educativo que vise qualidade, sem deixar nenhuma criança de lado, passa por aprendizagens sociais, onde aprender através da discussão é essencial, onde se fomenta a motivação e a autoestima e onde se proporciona um feedback constante (não sob forma de notas ou de recompensa/castigo, mas sim como comentários construtivos para que o aluno acredite que pode melhorar o seu desempenho). Esse sistema está ainda por ser construído na maior parte dos países. Para implementá-lo, precisamos de métodos educativos em que os programas sejam projetos de trabalho e não prescrições, precisamos de escolas que desenvolvam criatividade e diversidade, precisamos de professores qualificados e motivados. Precisamos também que as escolas transmitam conhecimento, desenvolvam todas as inteligências e valorizem as capacidades que de fato são importantes para a vida. 
As oito competências essenciais para a aprendizagem

As oito competências essenciais para a aprendizagem ao longo da vida, definidas na recomendação da União Europeia (EU) de 2006, ${ }^{3}$ dizem respeito a aptidóes que se revestem de particular importância para a criatividade e a capacidade de inovação. Em especial, são necessárias aptidōes e competências que permitam ao indivíduo encarar a mudança como uma oportunidade, manter-se receptivo a novas ideias e respeitar e apreciar os valores dos outros. Perante a evidência de que a diversidade e os ambientes multiculturais podem estimular a criatividade, as políticas de educação inclusivas, destinadas a fomentar a tolerância e a compreensão mútua, encerram o potencial de transformar o crescente multiculturalismo das sociedades europeias numa vantagem para a criatividade, a inovação e o crescimento.

A expressão cultural é listada como uma das oito competências necessárias para a aprendizagem ao longo da vida, referida também por mecanismos de certificação e validação como "Education \& Training 2010" e "European Qualifications Framework (EQF) for Lifelong Learning". Sem arte e educação através da arte a expressão cultural dos povos seria extremamente reduzida. A contribuição da arte para a cultura das comunidades é fundamental, assim como é fundamental que se promova educação de qualidade através da arte, atribuindo-lhe espaço e tempo curriculares adequados e estudando o seu impacto na sociedade.

A escola, para atingir estes fins, não é aquela que conhecemos, mas uma escola de confiança, valorizada pelo Estado e pela sociedade em geral e valorizadora das comunidades que a constituem. Só assim se poderá trabalhar em novas e diferentes redes, nomeadamente as ancoradas na comunidade local. As parcerias entre o sistema de ensino, o mundo do trabalho e a sociedade civil, em geral, são deveras cruciais para a antecipação e adaptação às necessidades em mutação da vida profissional e social: estágios profissionais, projetos conjuntos, aprendizagem entre pares e formadores vindos de fora do sistema de ensino podem dar a conhecer novas ideias a professores e alunos. Mas, para fazer essas redes, é necessário desburocratizar a escola. É preciso que o Estado reconheça a educação como fator-chave para o desenvolvimento econômico do país e invista nela, flexibilizando-a, encorajando os professores a desenvolver o seu papel profissional como mediadores de 
aprendizagem e promotores de criatividade; promovendo a produção cultural, o diálogo intercultural e a cooperação a nível local, regional, nacional e internacional, com vistas a desenvolver ambientes particularmente propícios à criatividade e à inovação, tal como é proposto pelo Conselho Europeu. E, para atingir tais metas, a educação através da arte tem um papel crucial.

A educação artística e a promoção da criatividade e da inovação

Segundo o Roteiro da Educação Artística ${ }^{4}$ publicado pela UNESCO (2006), as diferentes linguagens da arte oferecem aos jovens oportunidades únicas para compreenderem e criarem as suas identidades pessoais; estimulam os estudos interdisciplinares, a tomada de decisões participativas e motivam os jovens e as crianças para uma aprendizagem ativa, criativa e questionadora. Tendo isso em conta, será fácil entender a justificação para a centralidade da educação artística no ensino: a arte prepara os alunos para a incerteza do futuro, para responderem a problemas e para lidarem com tecnologias que ainda não foram desenvolvidas.

Existem estudos realizados que comprovam que os alunos com acesso a uma boa arte-educação, em qualquer área (musical, visual, drama, dança), desenvolveram capacidades inter e intrapessoais, são mais tolerantes, conseguem usar pensamento divergente e convergente, são mais curiosos, mais abertos à mudança, não têm medo de arriscar e são mais críticos do que alunos que não tiveram acesso a programas de educação artística. Elliot Eisner escreveu largamente sobre o assunto e Anne Bamford, no seu livro The WoW Factor, também o afirma. Na edição online do The New York Times de 4 de agosto de 2007, ${ }^{5}$ foi publicada notícia sobre os estudos de Ellen Winner, Lois Hetland, Shirley Veenema e Kimberly Sheridan, investigadoras do Harvard Project Zero, acerca do papel e dos benefícios da arte nas escolas. Segundo as autoras, as artes visuais teriam benefícios indiretos no desempenho escolar dos alunos. Aqueles com acesso a uma educação artística de qualidade teriam maior capacidade de visão e de previsão, seriam mais perseverantes, possuiriam mais capacidades lúdicas, teriam mais propensão a aprender através dos erros, seriam mais críticos e mais capazes de justificar as suas opiniōes. 
Qual o papel da educação através da arte para o desenvolvimento de um futuro sustentável?

Termino este texto com algumas questões enunciadas pelos organizadores para o próximo Congresso Europeu da International Society for Education Through the Arts (INSEA). Que tipo de educação através da arte, pela arte ou com a arte pode criar situaçóes de ensino e aprendizagem, nas quais se pode refletir sobre realidades socioculturais das comunidades locais e das comunidades globais, onde se possam fazer observaçōes profundas e criar uma consciência social responsável em relação ao ambiente e à sociedade, em relação ao local e ao global? Será que a educação através da arte cria essas situaçōes? Como as cria? Como desenvolve esse tipo de reflexôes? Como promove uma consciência crítica social? Como fomentar interações responsáveis, reflexão, diálogo, pensamento crítico e como pode ser um motor de transformação social?

Respostas para estas perguntas estão, neste momento, sendo enunciadas através da prática do ensino da arte em vários locais do mundo por educadoras e educadores criativos que não têm medo de transgredir rotinas, através de projetos de trabalho colaborativo, envolvendo muitas áreas do saber, integrando artistas e professores com capacidades de investigação, utilizando pedagogias refletivas e críticas com novos e antigos meios de produção artística.

Alfredo Palácios e Javier Abad Molina, por exemplo, desenvolvem em Espanha um trabalho fantástico, em que as fronteiras entre professor, investigador e artista se diluem nos diálogos críticos que suscitam na comunidade onde desenvolvem os seus projetos, a partir de palavras e de imagens (Garrido \& Molina, 2008).

Outro exemplo é o jovem arte-educador de Portugal Paulo D'Alva, que ajudou uma comunidade cigana da Rua da Baralha (Santa Maria da Feira, Norte de Portugal) a recuperar a sua dignidade e identidade social, com um atelier de cinema de animação (Carro Branco Carro Preto). Ou Lila Rosa Ferro, uma arte-educadora brasileira que colaborou no projecto "Awapa: nosso canto", construído a partir de uma rede de parcerias que visava a sustentabilidade da cultura Yaqwalapíti no alto Xingu, por meio da preservação da música popular. No livro que Ferro (2008) organizou para a comunidade Yawalapíti, a fala de Aritana resume uma das mais importantes razóes para o lugar crucial que a 
Educação através da arte para um futuro sustentável

educação artística deve ter na educação: "Então, eu estive pensando muita coisa à noite: como é que se pode fazer isso agora? Por que só uma pessoa tem os cantos? Só ele tem? E o resto? Não pode. Ele tem de passar isso já para os mais jovens...”.

Recebido em julho de 2008 e aprovado em março de 2010.

\section{Notas}

1. Jornal oficial da União Europeia (2007/C 287/01).

2. Working Group on 14-19 Reform (England). Disponível em: <www.dfes.gov.uk/14-19>.

3. Recomendação 2006/962/CE do Parlamento Europeu e do Conselho, de 18 de dezembro de 2006, sobre as competências essenciais para a aprendizagem ao longo da vida (JO L 394 de 30.12.2006, p. 10).

4. Disponível em: <http://portal.unesco.org/culture/en/ev.php-URL_ID=30335\&URL_ DO=DO_TOPIC\&URL_SECTION=201.html> Acesso em: mar. 2009.

5. Book Tackles Old Debate: role of art in schools. Disponível em: <http://query.nytimes.com/ gst/fullpage.html? res=9E06E6DC1538F937A3575BC0A9619C8B63>. Acesso em: mar. 2009.

\section{Referências}

DCMS. Creative Britain: new talents for a new economy; a strategy document for the creative industries. 2008. Disponível em: <http:// www.culture.gov.uk/Reference_library/Publications/ar-chive_2008/ cepPub-new-talents.htm>. Acesso em: 10 maio 2008.

EFLAND, A.D. Culture, society, art and education in a postmodern world. Comunicação apresentada na Conferência da INSEA, Taiwan, 1999.

FERRO, L.R.S. (Org.). Awapá: nosso canto Aldeia Yawalapiti; Comunidade Yawalapíti, terra indígena do Xingú. Brasília, DF: Ministério do Meio Ambiente; Secretaria de Extrativismo e Desenvolvimento Rural, 2008.

GARRIDO, A.P.; MOLINA, J.A. Escribir el lugar: collaborative projects in public spaces. International Journal of Education through Art, London, v. 4, n. 2, p. 195-206, 2008. 
HETLAND, L. et al. Studio thinking: the real benefits of visual arts education. New York: Columbia University; Teachers College, 2007. MÉSZÁROS, I. O desafio do desenvolvimento sustentável e a cultura da igualdade substantiva. Conferência proferida na Cimeira dos "Parlamentos Latino-Americanos" sobre a "dívida social e integração latino-americana”. Caracas, 10-13 jul. 2001.

POPE, R. Creativity: theory, history, practice. London: Routledge, 2005.

STEERS, J. Criatividade: ilusões, realidades e novas oportunidades. Imaginar, Porto, n. 51, p. 4-8, 2008.

WORLD ARTS ALLIANCE. Joint Declaration, 2006. Disponível em: <http://www.insea.org/docs/joint_decl2006.html>. Acesso em: 5 nov. 2008. 